\title{
DESENVOLVIMENTO DE Agave sisalana Perrine SOB DIFERENTES MANEJOS DE ADUBAÇÃO E CONSÓRCIO
}

Ana Beatriz Torres Melo de Freitas ${ }^{1}$, Annie Maia Batista Santos ${ }^{1}$, João Paulo de Oliveira Santos ${ }^{2}$, Jardel da Silva Souza ${ }^{1}$, Fábio Mielezrski ${ }^{1}$

${ }^{1}$ Universidade Federal da Paraíba - UFPB. ${ }^{2}$ Universidade Federal Rural de Pernambuco - UFRPE. E-mail: abeatriztmfreitas@gmail.com

\section{RESUMO}

O sisal (Agave sisalana Perrine) é uma cultura de grande importância para o Semiárido do Brasil, constituindo-se como uma importante fonte de renda para regiões anteriormente sem opções de desenvolvimento. No entanto, estudos quanto ao manejo da cultura são escassos, refletindo na baixa tecnificação e práticas arcaicas no sistema de produção. Nesse contexto, o presente trabalho teve como finalidade avaliar o desempenho do crescimento inicial do Sisal (Agave sisalana Perrine) sob diferentes fontes de adubação (química e orgânica) e sob a presença e ausência de consórcio com feijão (Phaseolus vulgaris), no município de Areia, Paraíba. O experimento foi conduzido em delineamento em blocos casualizados (DBC), sob esquema fatorial $2 \times 3$, sendo dois sistemas de cultivo (solteiro ou consorciado com feijão) e três manejos de adubação (orgânico, mineral e sem adubação), constituindo assim seis tratamentos e quatro repetições, totalizando 24 parcelas, cada uma com área de $25 \mathrm{~m}^{2}$. Os resultados evidenciaram a influência da fonte de adubação e do efeito do consórcio sob o desenvolvimento inicial da cultura, sendo os melhores resultados obtidos com adubação orgânica e consórcio com o feijão.

Palavras-chave: fibra; Phaseolus vulgaris; sisal.

\section{DEVELOPMENT OF Agave sisalana Perrine UNDER DIFFERENT FERTILIZATION MANAGEMENT AND INTERCROPPING}

\begin{abstract}
The Sisal (Agave sisalana Perrine) is a crop very important for the semi-arid region of Brazil, constituting an important source of income in regions that lack options that help in their development. However, studies regarding the development of this crop are scarce, reflecting on the low technology use and ancient practices used in the production systems. The object of this study was to evaluated the initial growth development of plants of Sisal (Agave sisalana Perrine) under different sources of chemical and organic fertilization and presence and absence of intercropping with common bean (Phaseolus vulgaris), in the city of Areia, Paraíba. The experiment was carried out in a randomized complete block design (RCBD), in a $2 \times 3$ factorial scheme, composed of two cultivation systems (alone or intercropped) and three fertilization types (organic, chemical and no fertilization), totaling 24 treatments with four replications in an area of $25 \mathrm{~m}^{2}$ each. The results showed an influence effect of the source of fertilization and the intercroppingon the initial development of the crop, and the best results obtained were with the organic fertilization and the intercropping with common bean.

Keywords: fiber; Phaseolus vulgaris; sisal.
\end{abstract}

\section{INTRODUÇÃO}

O sisal (Agave sisalana Perrine) é uma planta oriunda do México que apresenta um amplo campo de utilização. Da extração e beneficianento de suas folhas, se produz uma fibra de excelente qualidade, a qual se destina a fabricação de diversos tipos de fios para a mais varidas utilidades, sendo muito bem aceita no mercado internacional. Ademais, a seiva que é oriunda de suas folhas contém hecogenina, utilizada na síntese da droga cortisona. Os resíduos do desfibramento podem produzir 
pectato de sódio e cera, já o pendão floral é bastante utilizado na construção de cercas (ALVARENGA JÚNIOR, 2012).

O Brasil é o maior produtor e exportador mundial de sisal. Estima-se que $80 \%$ da produção brasileira é direcionada ao mercado externo (NAVES, 2015). No país a planta é cultivada predominantemente na região Semiárida (BATISTA et al., 2010), merecendo destaque o estado da Bahia, responsável por 95,8\% da área cultivada no território brasileiro, os $4,2 \%$ restantes estão localizados na Paraíba (3,5\%), Ceará $(0,4 \%)$ e Rio Grande do Norte $(0,3 \%)$ (NAVES, 2013).

O Semiárido brasileiro historicamente sofre com questões de irregularidades pluviométricas, o que compromete drasticamente as atividades agrícolas e pecuárias (MARENGO et al., 2011; BATSITA et al., 2018). Nesse sentido, culturas como o sisal, que são adaptadas as essas condições, representam uma alternativa para o desenvolvimento de atividades produtivas nessas áreas, gerando emprego e renda em ambientes que anteriormente apresentavam pouca ou nenhuma opção econômica (ALVES; SANTIAGO, 2006).

Embora seja cultivado em larga escala, o sisal é ainda explorado com baixo índice de modernização, e com práticas culturais arcaicas o que tem levado a redução da área plantada e na produção. Somado a esses fatores, o baixo valor pago pela fibra, o reduzido índice de aproveitamento da planta (somente 3 a $5 \%$ das folhas colhidas se convertem em produto comercial), a concorrência com as fibras duras sintéticas, o elevado custo inicial para implantação e manutenção da lavoura e a falta de variedades mais produtivas tem colaborado para o declínio da cultura no Semiárido (BRASIL, 2011).

A situação é ainda mais complexa na Paraíba, estado que na década de 1970 detinha a hegemonia da produção brasileira de sisal, status que a partir 1990 passou a ser ocupado pela Bahia (ALVES; SANTIAGO, 2006). A produção da cultura na Paraíba está concentrada em 27 municípios, sendo Picuí, Barra de Santa Rosa, Casserengue, Remígio e Pocinhos as localidades que lideram a produção (IBGE, 2006).

Diante dessa conjuntura, tomando como base a carência de trabalhos a nível científico realizados com a cultura, faz-se necessário aprimorar as pesquisas voltadas para o sisal, buscando-se determinar as formas de manejo adequadas para a região Nordeste, tendo como finalidade a sua expansão. Assim, o presente trabalho objetivou identificar a forma de manejo a ser utilizada no crescimento inicial em plantas de Sisal (Agave sisalana Perrine), estudando os efeitos de tipos de adubação (química e orgânica) e com a presença e ausência de consórcio com o feijão (Phaseolus vulgaris).

\section{MATERIAL E MÉTODOS}

O experimento foi desenvolvido na Fazenda Experimental Chã do Jardim, pertencente ao Centro de Ciências Agrárias da Universidade Federal da Paraíba, situada no município de Areia na Microrregião do Brejo Paraibano, com coordenadas geográficas $6^{\circ} 58^{\prime} 11^{\prime \prime} \mathrm{S} 35^{\circ} 44^{\prime} 00^{\prime \prime} \mathrm{W}$ a $623 \mathrm{~m}$ de altitude. $\mathrm{O}$ clima, segundo a classificação de Köppen, é do tipo As' (quente e úmido) com chuvas de outono- inverno, com período de estiagem de 5 a 6 meses. O experimento foi conduzido de junho a dezembro de 2017.

$\mathrm{O}$ solo da área experimental foi coletado e em seguida classificado como Latossolo Vermelho-Amarelo (EMBRAPA, 2006), sendo encaminhado para a realização de análise química no Laboratório de Química e Fertilidade do Solo pertencente ao Departamento de Solos e Engenharia Rural (CCA/UFPB), estando os valores encontrados na Tabela 1.

Tabela 1. Características químicas do solo, na camada de 0 a $20 \mathrm{~cm}$ antes da instalação do experimento.

\begin{tabular}{|c|c|c|c|c|c|c|c|c|c|}
\hline pH & $\mathbf{P}$ & K & $\mathrm{Na}$ & $\mathrm{H}+\mathrm{Al}$ & Al & $\mathrm{Ca}$ & Mg & СТC & MO \\
\hline & $\mathrm{mg} \mathrm{C}$ & & & &.. $\mathrm{cmc}$ & $n-3 \ldots$ & & & ....gKg.... \\
\hline 4,8 & 2,4 & 28,4 & 0,05 & 5,49 & 0,1 & 0,81 & 0,3 & 6,3 & 36,72 \\
\hline
\end{tabular}

A área experimental corresponde a 1050 $\mathrm{m}^{2}(35 \times 30 \mathrm{~m})$, sendo o experimento instalado em delineamento em blocos casualizados (DBC), sob esquema fatorial $2 \times 3$, sendo dois sistemas de 
cultivo (solteiro e consorciado com feijão) e três manejos de adubação (orgânico, mineral e sem adubação), constituindo assim seis tratamentos e quatro repetições, totalizando 24 parcelas, cada uma com área de $25 \mathrm{~m}^{2} \quad(5 \times 5 \mathrm{~m})$, apresentando quatro linhascom quatro plantas, totalizando 16 plantas por parcela. 0 espaçamento entre plantas foi de $1 \mathrm{~m}$, definido com base na recomendação da EMATER-PB (1984), para os municípios do estado da Paraíba.

Os tratamentos utilizados foram: T1: Sisal consorciado com o feijão + adubação orgânica (esterco bovino); T2: Sisal consorciado com o feijão + adubação química (NPK); T3: Sisal consorciado com o feijão, sem adubação; T4: Sisal com adubação orgânica; T5: Sisal com adubação química; T6: Testemunha (o sisal transplantado em fileira única, sem receber adubação).

A dosagem da adubação química foi definida através da recomendação determinada por Malavolta (2006). De acordo com a dosagem recomendada, associando-se com a análise química realizada no solo, os tratamentos $\mathrm{T} 2 \mathrm{e}$ T5 receberam $20 \mathrm{~kg} \mathrm{ha}^{-1}$ de nitrogênio, antes do transplantio e $40 \mathrm{~kg} \mathrm{ha}^{-1}$ na cobertura; $70 \mathrm{~kg} \mathrm{ha}^{-1}$ de $\mathrm{P}_{2} \mathrm{O}_{5}$ no transplantio e $35 \mathrm{~kg} \mathrm{ha}^{-1}$ de $\mathrm{K}_{2} \mathrm{O}$ antes do transplantio.

Quanto à adubação orgânica, na qual utilizou-se esterco bovino nos tratamentos T1 e T4, não há estudos que recomendem uma quantidade a ser utilizada na cultura do sisal, usando-se assim como base a dosagem de $20 \mathrm{t}$ $\mathrm{ha}^{-1}$, geralmente recomendada para outras grandes culturas.

As mudas de sisal foram adquiridas no município de Pocinhos, Paraíba, através de doação de um produtor da região. Logo após o transplantio foi realizada a adubação nas plantas pertencentes aos tratamentos $\mathrm{T} 1, \mathrm{~T} 2$, T4 e T5. $\mathrm{O}$ feijão (Phaseolus vulgaris), utilizado no consórcio com o sisal foi semeado na semana seguinte ao transplantio do sisal, onde foram semeadas duas linhas de feijão, entre cada linha de sisal com população de 250 mil plantas por hectare.

Foram realizadas cinco avaliações: a primeira denominada avaliação inicial, foi realizada quinze dias após o transplantio; a segunda avaliação um mês e quinze dias após a primeira, a terceira, quarta e quinta avaliação aconteceram um mês e quinze dias após a anterior. Sendo avaliada quatro plantas por parcela, eliminando-se as bordaduras e utilizando-se as plantas centrais.

As variáveis utilizadas para avaliar as plantas foram: altura de planta, número de folhas, altura de uma determinada folha, largura dessa folha e sua espessura. Sendo determinadas da seguinte forma: Taxa de crescimento de altura de planta: para calcular essa taxa, a planta foi medida com fita métrica do início de seupseudocaule; Número de folhas novas: foram contadas o número de folhas daplanta; Taxa de crescimento de altura da folha: a folha escolhida foi demarcada com uma fita, sua medida com fita métrica iniciava-se na sua inserção ao pseudocaule; Taxa de crescimento de largura da folha: a folha demarcada foi medida com fita métrica em seucentro; Taxa de crescimento de espessura da folha: a folha demarcada foi medida com o auxílio do paquímetro à mesma altura da medida da largura.

Os dados de precipitação pluviométrica, temperatura e insolação durante o período de estudo foram obtidos junto a estação meteorológica do Centro de Ciências Agrárias da UFPB.

Os dados foram submetidos a análise de variância (ANOVA) e a teste de regressão polinomial para os diferentes dias de avaliação, testando-se modelos de até segundo grau e admitindo-se coeficiente de determinação a partir de $70 \%$, com significância do modelo em até 5\%. Utilizou-se o software SAS 9.3 (2011) para as análises.

\section{RESULTADOS E DISCUSSÃO}

A temperatura média durante o período de experimento manteve-se entre $19-30{ }^{\circ} \mathrm{C}$, o que configura uma condição térmica excelente para o cultivo do sisal, já que Brasil (2011) aponta que o clima ideal para o crescimento e desenvolvimento dessa cultura é o quente, com temperatura média anual entre $20-28^{\circ} \mathrm{C}$.

A pluviosidade manteve-se dentro do necessário para um bom desenvolvimento do sisal, sendo contabilizados $911,9 \mathrm{~mm}$ durante o período em campo. A exigência hídrica da cultura é de no mínimo $400 \mathrm{~mm}$ anual, desenvolvendo-se bem em regiões com média superior a $1000 \mathrm{~mm}$ ano $^{-1}$ (SUINAGA et al., 2006).

Quanto à insolação, foram registradas 1463,5 horas de sol, taxa considerada propícia para o bom desenvolvimento da cultura. Essa 
variável é muito importante ao se trabalhar com o sisal, uma vez que, se durante o desenvolvimento da planta os dias não forem ensolarados, as folhas tornam-se flácidas, diminuindo o vigor e enfraquecendo as fibras (SILVA et al., 2008).

Plantas de sisal em ambos os cultivos solteiro e consorciado com feijão, sofreram influência significativa de acordo com o tipo de adubação utilizado ( $\leq \leq 0,0001)$, crescendo linearmente dos 58 até os 193 dias após o transplantio, destacando-se principalmente o sistema de adubação química (CAQ e SAQ) e consorciado sem adubação (CSA) nos últimos dias de avaliação (Figura 1). De acordo com Taiz et al. (2017), o alongamento celular e o desenvolvimento/crescimento das plantas são regulados principalmente pelas auxinas, mas este hormônio tem sua ação fortemente regulada quando as plantas estão adequadamente nutridas. Trabalhos recentes demonstram que as auxinas atuam juntamente com o etileno e as espécies reativas de oxigênio em vias de sinalização que respondem a deficiência de nutrientes como potássio, fósforo, enxofre, ferro (GARCÍA et al., 2015) e boro (CAMACHO-CRISTÓBAL et al., 2015) e o bom desempenho das plantas demanda todos esses nutrientes em níveis específicos para cada espécie. Dessa forma, a adubação química demonstrou suprir melhor as demandas da cultura do sisal, a curto prazo, promovendo maior crescimento das folhas em relação as plantas do cultivo orgânico. Sendo muito importante já que a fase inicial da planta é aquela em que ocorre a adaptação ao ambiente e às condições nutritivas necessárias.

Figura 1. Crescimento da planta de sisal em cultivo solteiro e consorciado com feijão sob adubação orgânica e química durante 150 dias após transplantio. CAO (Consorciado + Adubação Orgânica); CAQ (Consorciado + Adubação Química); CSA (Consorciado + Sem Adubação); SAO (Solteiro + Adubação Orgânica); SAQ (Solteiro + Adubação Química); SSA (Solteiro+ Sem Adubação). **significativo a 1\%.

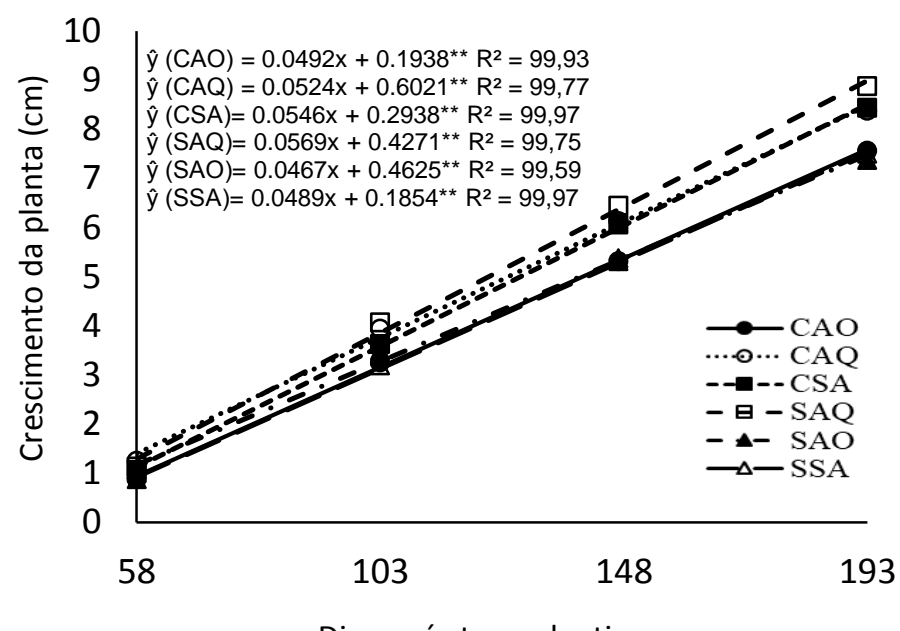

Dias após transplantio

O ganho em número de folhas novas para plantas de sisal foi linear entre os 58 e 193 dias após o transplantio para os diferentes sistemas de cultivo e adubação (Figura 2). Observou-se ainda efeito significativo $(p \leq 0,0001)$ para os diferentes manejos de adubação e para a interação manejo de adubação (MA)/sistemas de cultivo (SC). Nesse contexto, o sistema de cultivo consorciado e sob adubação orgânica (CAO), destacou-se dos demais por proporcionar maior número de folhas novas em plantas de sisal. O esterco bovino é um composto orgânico de rápida taxa de degradação, quando comparado a outros compostos orgânicos, com consequente liberação dos nutrientes para as plantas (SOUTO et al., 2005), além de melhorar as propriedades físicas do solo (MARSCHNER, 2012) o que possivelmente contribui para maior ganho em número de folhas pela cultura do sisal. 
Figura 2. Número de folhas novas em planta de sisal em cultivo solteiro e consorciado com feijão sob adubação orgânica e química durante 150 dias após transplantio. CAO (Consorciado + Adubação Orgânica); CAQ (Consorciado + Adubação Química); CSA (Consorciado + Sem Adubação); SAO (Solteiro + Adubação Orgânica); SAQ (Solteiro + Adubação Química); SSA (Solteiro + Sem Adubação). **significativo a 1\%.

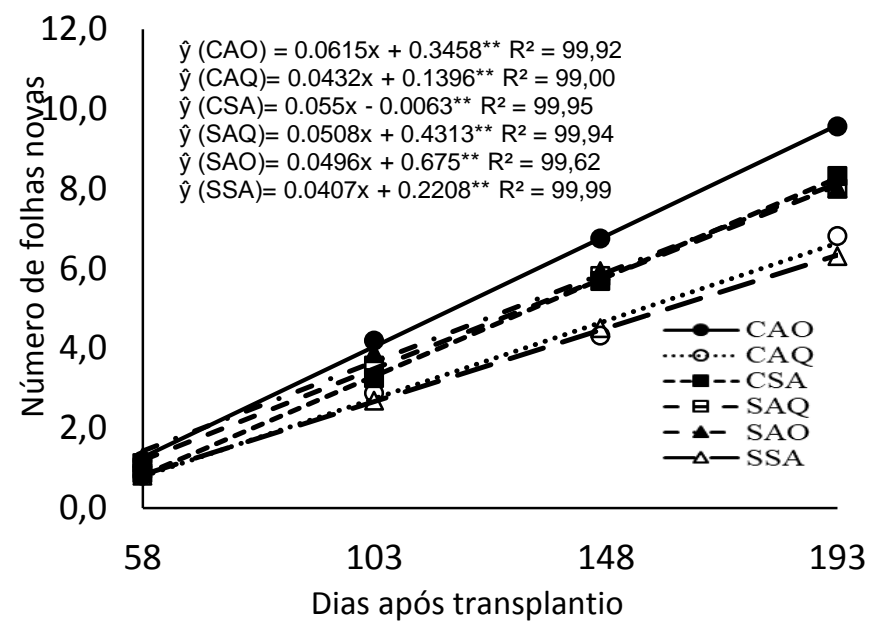

O crescimento de uma determinada folha das plantas de sisal foi linear em função do tempo, tendo sofrido influência significativa $(p \leq 0,0001)$ da interação entre adubação e consórcio (Figura 3). O maior crescimento da folha foi observado quando utilizado os sistemas Consorciado com Adubação Orgânica (CAO) e Sem Adubação (CSA), enquanto que para o sistema Solteiro, apenas quando foi aplicado a Adubação Química (SAQ) os resultados foram melhores em relação aos demais tratamentos desse sistema. As folhas correspondentes a esses tratamentos obtiveram um aumento em seu crescimento após os 50 dias de transplantio, nos meses de agosto a dezembro, período em que apresentaram as maiores taxas de insolação no município de Areia, o que pode ter favorecido o crescimento das folhas de sisal.

Figura 3. Altura de uma determinada folha em planta de sisal em cultivo solteiro e consorciado com feijão sob adubação orgânica e química durante 150 dias após transplantio. CAO (Consorciado + Adubação Orgânica); CAQ (Consorciado + Adubação Química); CSA (Consorciado + Sem Adubação); SAO (Solteiro + Adubação Orgânica); SAQ (Solteiro + Adubação Química); SSA (Solteiro + Sem Adubação). **significativo a $1 \%$.

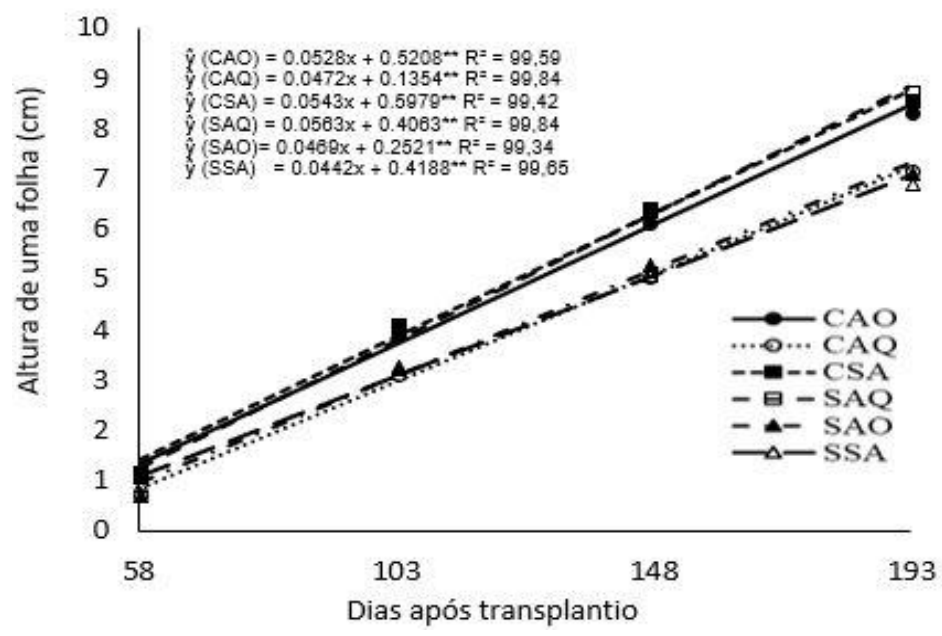

Independentemente do sistema de adubação, o consórcio influenciou significativamente a $5 \%$ de probabilidade a variável largura da folha (Figura 4). De maneira geral, o sistema de cultivo consorciado promoveu maior ganho em largura da folha que o sistema de cultivo solteiro. O feijão, espécie consorciada, funciona como adubação verde, já 
que as leguminosas fixam nitrogênio e geram uma biomassa rica (EMBRAPA, 2005). Castro et al., (2000) verificaram que a produção de matéria seca das plantas usadas na adubação verde e na cobertura do solo, antes do plantio da berinjela, variou de 4,5 a 6,5 $\mathrm{mg} \mathrm{ha}^{-1}$, o que representou um acúmulo de 51 a $126 \mathrm{~kg} \mathrm{ha}^{-1}$ de N. O ganho em largura da folha foi sempre linear em todos os sistemas de cultivo e não foi influenciado pela adubação.

Figura 4. Largura de uma folha em planta de sisal em cultivo solteiro e consorciado com feijão sob adubação orgânica e química durante 150 dias após transplantio. CAO (Consorciado + Adubação Orgânica); CAQ (Consorciado + Adubação Química); CSA (Consorciado + Sem Adubação); SAO (Solteiro + Adubação Orgânica); SAQ (Solteiro + Adubação Química); SSA (Solteiro + Sem Adubação). *significativo a 5\%.

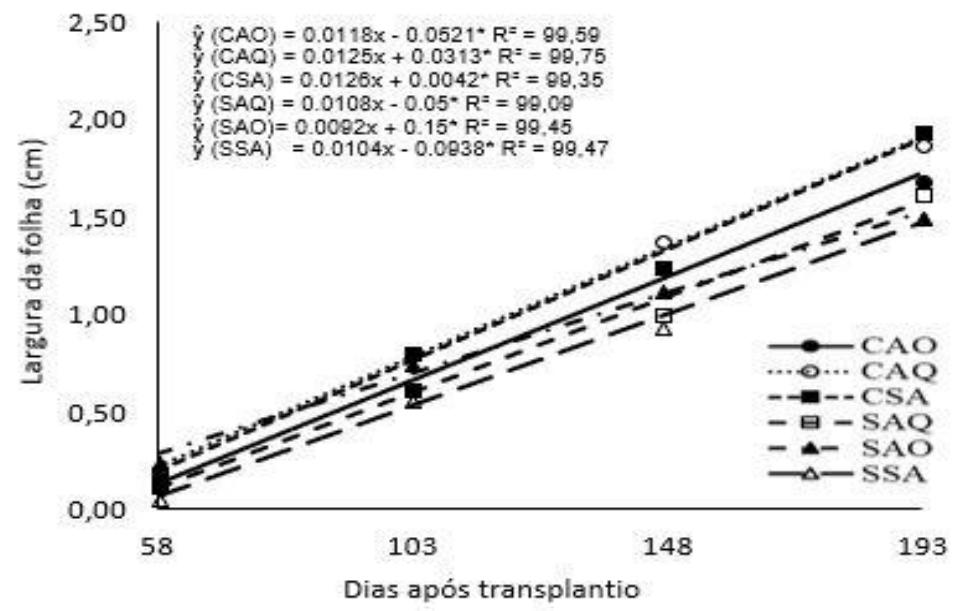

A espessura da folha foi influenciada pelo sistema de cultivo isoladamente $15 \%$ de probabilidade) e pelo manejo de adubação ( $p \leq 0,0001$ ) (Figura 5). O sistema de Adubação Orgânica promoveu maior ganho em espessura da folha em ambos os sistemas Consorciado (CAO) e Solteiro (SAO). A aplicação de esterco proporciona aumento significativo no $\mathrm{pH}$ e nos teores de todos os elementos na camada de 0 $20 \mathrm{~cm}$. Onde a repetitiva adubação com o esterco, vai potencializar a presença desses nutrientes (GALVÃO et al., 2008). Essa disponibilização de nutrientes, no crescimento inicial, proporciona uma maior disponibilidade de potássio, influenciando na produção de massa verde da planta nos primeiros meses de cultivo.

Figura 5. Espessura da folha em planta de sisal em cultivo solteiro e consorciado com feijão sob adubação orgânica e convencional durante 150 dias após transplantio. CAO (Consorciado + Adubação Orgânica); CAQ (Consorciado + Adubação Química); CSA (Consorciado + Sem Adubação); SAO (Solteiro + Adubação Orgânica); SAQ (Solteiro + Adubação Química); SSA (Solteiro + Sem Adubação). ** significativo a $1 \%$.

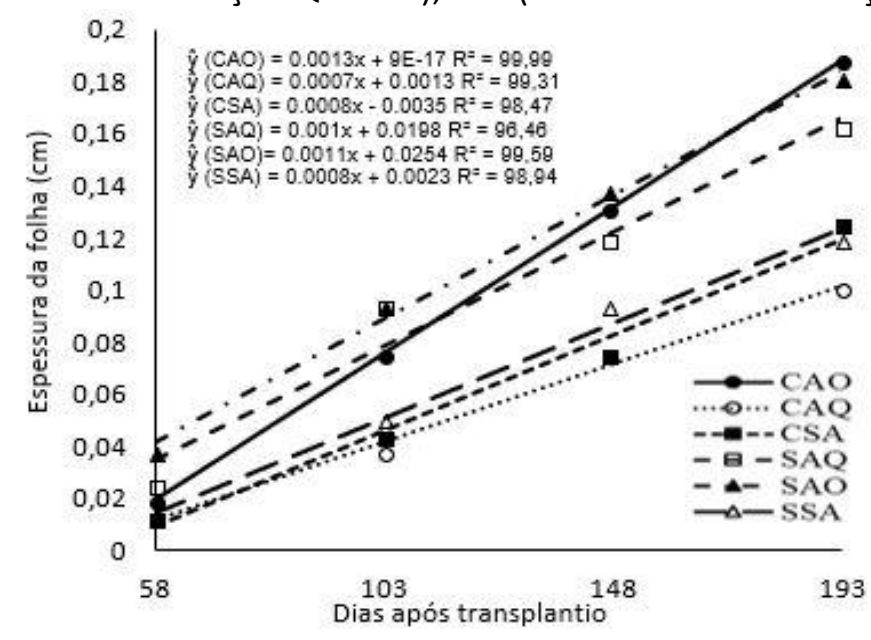


Avaliando em conjunto, observa-se que o desenvolvimento inicial das plantas de sisal em cultivo solteiro ou consorciado, sob adubação orgânica, química e sem adubação, ocorreu de forma linear para o período de 58 até 193 dias após o transplantio, indicando que as plantas continuam com desenvolvimento continuo diário e é necessário um maior período de avaliação para observar de forma mais adequada todos os efeitos dos fatores em estudo, bem como entender o padrão de crescimento dessa cultura nestas condições de cultivo, por se tratar de uma cultura com ciclo de vida longo e que varia muito em decorrência de diferentes condições edafoclimáticas e de manejo (MEDINA, 1951). Por sua vez, o sistema de cultivo consorciado com o feijão promove um bom desempenho da cultura principalmente se combinado com sistema de adubação orgânica, apresentando bom desenvolvimento inicial das plantas de sisal durante os primeiros meses no campo de produção, sendo a forma de manejo o elemento chave, para o bom desempenho da planta e melhor acúmulo de massa em virtude de obter o produto final que é a folha, nos primeiros meses.

\section{CONCLUSÃO}

A associação do consórcio com feijão e a adubação orgânica proporcionou desempenho superior no desenvolvimento inicial das plantas de sisal;

A utilização da adubação orgânica, por ser de baixo custo e não afetar negativamente o meio ambiente, mostrou-se uma alternativa importante para o cultivo do Sisal;

O consórcio com feijão, permite ao agricultor uma outra opção de renda e a maximização de seu espaço produtivo.

\section{REFERÊNCIAS}

ALVARENGA JÚNIOR, E. R. Dossiê Técnico cultivo e aproveitamento do sisal. Fundação Centro Tecnológico Minas Gerais, 2012. 33 p.

ALVES, M. O.; SANTIAGO, E. G. Tecnologia e Relações Sociais de Produção no Setor Sisaleiro Nordestino. Revista Econômica do Nordeste, v. 37, n. 3, 2006.

BATISTA, D. C.; SILVA, F. M. ; SOUZA, W. C. O. ; BARBOSA, M. A. G. ; Costa, V. S. O. ; BRANDÃO, W. N. ; TERAO, D. Manejo da podridão vermelha do tronco do sisal. Petrolina: Embrapa Semiárido, 2010. (Circular Técnica 92).

BATISTA, M. C.; SANTOS, J. P. O.; SILVA FILHO, J. A.; SOUSA, J. I.; FELIX, R. J. S.; SILVA, J. L. C. Influence of rainfall variability on bean production (Phaseolus vulgaris L.) in a municipality of Brazilian semiarid. Journal of Environmental Analysis and Progress, v. 3, n. 1, p. 001-007, 2018 https://doi.org/10.24221/jeap.3.1.2018.1590.00 1-007

BRASIL. Ministério da Agricultura Pecuária e Abastecimento. Departamento de Gestão de Risco Rural. Portaria $n^{\circ}$ 326, de 17 de agosto de 2011. Aprova o Zoneamento Agrícola de Risco Climático para a cultura de sisal no Estado da Bahia. 2011.

CAMACHO-CRISTÓBAL, J. J.; MARTÍN-REJANO, E. M.; HERRERA-RODRÍGUEZ, M. B.; NAVARROGOCHICOA, M. T.; REXACH, J.; GONZÁLEZFONTES, A. Boron deficiency in hibits rootcell elongation via anethylene/auxin/ROSdependentpathway in Arabidopsis seedlings. Journal of Experimental Botany, v. 66, n. 13, p.3831-3840, 2015. https://doi.org/10.1093/ixb/erv186.

CASTRO, C. M.; ALVES, B. J. R.; ALMEIDA, D. L.; RIBEIRO, R. L. D. Adubação verde com o fonte de nitrogênio para a cultura da berinjela em sistema orgânica. Pesquisa Agropecuária Brasileira, v.39, n.8, p.779-785, 2004. https://doi.org/10.1590/S0100-

204X2004000800008.

EMATER-PB. Sistema de produção de sisal para as microrregiões do curimataú, seridó paraibano e cariris velhos - PB. João Pessoa, 1984. (Sistema de Produção)

EMBRAPA. Adubação verde como leguminosa. Brasília. 2005. (Soluções tecnológicas). Disponível em: https://www.embrapa.br/buscade-publicacoes/-/publicacao/627202/adubacaoverde-com-leguminosas. Acesso em: 07 jan. 2018.

EMBRAPA. Sistema brasileiro de classificação de solos. 2. ed. Rio de Janeiro, 2006. 305 p. 
GALVÃO, S. R. S.; SALCEDO, I. H.; OLIVEIRA, F. F. Acumulação de nutrientes em solos arenosos adubados com esterco bovino. Pesquisa Agropecuária Brasileira, v.43, n.1, p.99-105, $2008 . \quad$ https://doi.org/10.1590/S0100$\underline{204 \times 2008000100013}$

GARCÍA, M. J., ROMERA, F. J., LUCENA, C., ALCÁNTARA, E., PÉREZ- VICENTE, R. Ethylene and the regulation of physiological and morphological responses to nutrient deficiencies. Plantphysiology, v. 169 , n. 1, p. 5160, 2015. https://doi.org/10.1104/pp.15.00708.

IBGE. Produção Agrícola Municipal, Lavoura Permanente, Sisal. 2006. Disponível em: http: // cod.ibge.gov.br/3BT08. Acesso em: 12 dez. 2017.

MALAVOLTA, E. Manual de nutrição mineral de plantas. São Paulo: Agronômica Ceres, 2006. $638 p$.

MARENGO, J. A.; ALVES, L. M.; BESERRA, E. A.; LACERDA, F. F. Variabilidade e mudanças climáticas no semiárido brasileiro. In: Recursos Hidricos e, Regiões Aridas e Semiaridas. Campina Grande: INSA, 2011. p. 383-416.

MARSCHNER, $H$. Marschner's mineral nutrition of higher plants. 3. ed. London: Academic Press, 2012. 672p. https://doi.org/10.1016/C2009-063043-9.

MEDINA, J. C. Efeito da frequência e severidade de corte das folhas sobre a duração de vida do sisal. Bragantia, v. 11, n. 1-3, p. 19-22,1951. https://doi.org/10.1590/S000687051951000100003.

NAVES, I. M. Safra 2012/2013: comercialização proposta de ações. $2013 . \quad$ Disponível em: http://www.conab.gov.br. Acesso em: 20 nov. 2017.

NAVES, I. M. Sisal 2015 : Retrospectiva. 2016. Disponível em: http://www.conab.gov.br. Acesso em: 12 set. 2017.

SILVA, O. R. R. F.; COUTINHO, W. M.; CARTAXO, W. V.; SOFIATTI, V.; SILVA FILHO, J. L.; CARVALHO, O. S.; COSTA, L. B. Cultivo do sisal no nordeste brasileiro. Campina Grande: Embrapa Algodão, 2008. (Circular Técnica; 123)
SOUTO, P. C., SOUTO, J. S., SANTOS, R. V., ARAÚJO, G. T., SOUTO, L. S. Decomposição de estercos dispostos em diferentes profundidades em área degradada no semi-árido da Paraíba. Revista Brasileira de Ciência do Solo, v. 29, n. 1, p.125-130, 2005. https://doi.org/10.1590/S0100$\underline{06832005000100014 .}$.

SUINAGA, F. A.; SILVA, O. R. R. F.; COUTINHO, W. $M$. Sisal: recomendações técnicas. Campina Grande: Embrapa Algodão, 2006. Disponível em: http://sistemasdeproducao.cnptia.embrapa.br/F ontesHTML/Sisal/CultivodoSisal/index.html. Acesso em: 07 jan. 2018.

TAIZ, L.; ZEIGER, E.; MOLLER, I.M.; MURPHY, A. Fisiologia e desenvolvimento vegetal. 6. ed. Porto Alegre: Artmed, 2017. 888 p.

Recebido para publicação em 30/07/2018

Revisado em 04/01/2019

Aceito em 05/01/2019 